\title{
Amyloid-beta peptide and phosphorylated tau in the frontopolar cerebral cortex and in the cerebellum of toothed whales: aging vs hypoxia
}

Simona Sacchini ( $\square$ simona.sacchini@ulpgc.es )

Universidad de las Palmas de Gran Canaria https://orcid.org/0000-0001-6493-1275

Josué Díaz

Texas A\&M University College Station

Antonio Espinosa de los Monteros

Universidad de las Palmas de Gran Canaria

Yania Paz

Universidad de las Palmas de Gran Canaria

Yara Bernaldo de Quirós

Universidad de Las Palmas de Gran Canaria

\section{Eva Sierra}

Universidad de las Palmas de Gran Canaria

Manuel Arbelo

Universidad de las Palmas de Gran Canaria

\section{Pedro Herráez}

Universidad de Las Palmas de Gran Canaria - Campus de San Cristobal

\section{Antonio Fernández}

Universidad de las Palmas de Gran Canaria

\section{Research article}

Keywords: neurodegenerative diseases, toothed whales, beaked whales, diving, hypoxia, neurofibrillary tangles, granulovacuolar degeneration, beta amyloid

Posted Date: March 12th, 2020

DOI: https://doi.org/10.21203/rs.3.rs-17031/v1

License: (c) (1) This work is licensed under a Creative Commons Attribution 4.0 International License.

Read Full License 
Version of Record: A version of this preprint was published at Biology Open on January 1st, 2020. See the published version at https://doi.org/10.1242/bio.054734. 


\section{Amyloid-beta peptide and phosphorylated tau in the}

\section{2 frontopolar cerebral cortex and in the cerebellum of}

\section{3 toothed whales: aging vs hypoxia}

4

5

Sacchini Simona ${ }^{{ }^{*},}$, Díaz Josué ${ }^{2,3}$ Espinosa de los Monteros Antonio ${ }^{1}$, Paz Yania ${ }^{1}$, Bernaldo de Quirós

6 Yara ${ }^{1}$, Sierra Eva ${ }^{l}$, Arbelo Manuel ${ }^{1 *}$, Herráez Pedro $^{l}$, Fernández Antonio $^{l}$

7

$8{ }^{1}$ Veterinary Histology and Pathology, Institute of Animal Health, University of Las Palmas de Gran

9 Canaria, Veterinary School, c/Transmontaña s/n, 35416, Arucas

$10{ }^{2}$ Laboratory of Wildlife Comparative Pathology, School of Veterinary Medicine and Animal Science,

11 University of São Paulo, Brazil

$12{ }^{3}$ Texas A\&M Veterinary Medical Diagnostic Laboratory, College Station, TX 77843, US

13

14

15

Correspondence:

$16 \quad \underline{\text { simona.sacchini@ulpgc.es }}$

17 manuel.arbelo@ulpgc.es

18

19

20

21

22

23

24

25

26

27

28

29 


\section{ABSTRACT}

2 Background: Alzheimer's disease results from the interplay of multiple risk factors and their effects.

3 Diving mammals may be routinely exposed to severe hypoxia when submerged. Among toothed whales,

4 the beaked whales are particularly cryptic and routinely dive deeper than $1,000 \mathrm{~m}$ for about one hour in

5 order to hunt deep-water squid and fish. We hypothesized that hypoxia could be a possible risk factor for

6 neurodegenerative alterations in the central nervous system of beaked whales in particular, and toothed

7 whales in general.

8 Results: Samples of frontal cerebral cortex and cerebellum were collected from nine animals, representing

9 six different species of the suborder Odontoceti. Immunohistochemical analysis employed a monoclonal

10 anti- $\beta$-amyloid (A $\beta$ ) and a polyclonal anti-neurofibrillary tangle (NFT) antibodies.

11 Six of nine (67\%) animals showed positive immunolabeling for $A \beta$ and/or NFT. The most striking findings

12 were intranuclear $A \beta$ immunopositivity in cerebral cortical neurons and NFT immunopositivity in

13 cerebellar Purkinje neurons with granulovacuolar degeneration.

14 Herein, we present immunohistopathological findings classic of Alzheimer's and other neurodegenerative 15 diseases in humans, in different brain locales of odontocete cetaceans. This study represents the first 16 description of A $\beta$ and NFT in the brain of beaked whales, adding also to the non-existent descriptions of

17 GVD in the brain of non-experimental animals, being specifically the first report of granulovacuolar 18 degeneration in the cerebellum. Our results further confirm the rarely reported intranuclear expression of $19 \mathrm{~A} \beta$.

20 Conclusions: These findings could be linked to hypoxic phenomena, as they were more extensive in the 21 brains of beaked whales, and not only in aged individuals. Therefore, a novel hypothesis linking hypoxia 22 and neurodegeneration microscopic hallmarks in cetaceans is proposed. Despite their adaptations, diving 23 mammals could be vulnerable to sustained and repetitive brain hypoxia. Future comparative pathological 24 and neuroprotective investigations may prove of great value to Alzheimer's disease and other neurodegenerative diseases in humans.

\section{Key words:} granulovacuolar degeneration, beta amyloid 


\section{BACKGROUND}

Over 46 million people live with dementia worldwide and this number is estimated to attain global epidemic dimensions (131.5 million people) by 2050 [1]. Alzheimer's disease (AD) is a complex, multifactorial disease for which a number of genetic, environmental, and lifestyle risk factors have been identified [2]. Although there is a considerable body of knowledge on AD, this challenging disease of the new millennium is still considered a conundrum. Substantial research is in progress to understand the pathogenetic mechanisms of the disease and thus, to pursue a cure. Novel approaches on AD have identified a variety of neuroprotective phenomena. The pathologic hallmarks of $\mathrm{AD}$ are represented by the accumulation of beta-amyloid (A $\beta$ ) and neurofibrillary tangles (NFT) in neurons, neuroglia and neuroparenchyma, leading to neuronal and synaptic loss, and eventual brain atrophy [3].

A $\beta$ comprises a 36 to 43 amino acids long peptide of the amyloid precursor protein (APP) hydrolysis. Indeed, the A $\beta$ peptide is produced from APP through sequential cleavage of $\beta$ - and $\gamma$ secretases while A $\beta$ removal is dependent on the proteolysis and lysosome degradation system [3]. A $\beta$ accumulates intracellularly and is the major component of the extracellular (neuroparenchymal) plaques found in $\mathrm{AD}$ brain tissue. Recent studies have suggested common mechanisms underlying neurodegenerative depositional diseases such as AD, Parkinson, or Huntington disease. Formation of amyloid-like protein aggregates unifies these superficially unrelated pathologies $[4,5]$.

NFT are composed of insoluble paired helical filaments of a highly phosphorylated form of the microtubule-associated protein $\tau$ (tau), and associated lipid. While typical NFT in central nervous system (CNS) have been reported in senior cats, increased phosphorylation of $\tau$ without typical NFT has been described in sheep and goat (Cetartiodactyla), cat, dogs, leopards, cheetah, bison, degu, wolverine, bear, American bison, [6]. In these cases, the $\tau$ changes tend to be sporadic and do not adopt 'full blown' features as seen in humans [6]. Again, evidence that A $\beta$ pathology increases with age was reported in a large number of non-human primate species, New and Old World monkeys [6-8], and some great apes like the western lowland gorilla $[9,10]$. On the contrary, NFT have rarely been described in non-human primate brain with the exception of a single aged chimpanzee [11] and in the gray mouse lemur [12]. Interestingly, some potential longevity in humans is much longer than great apes (40 to 55 years) [10] or even some species like the gray mouse lemur (Microcebus murinus) which is considered to be elderly over 5 years of age [12]. On the other side, the maximum recorded lifespan in the killer whale (Orcinus orca) is 78 years, in the short-finned pilot 
whale is 63 years, and in the striped dolphin is 58 years $[13,14]$. However, the choose of an ideal animal natural model is hampered by which animal appear to show species specific variations in the process of phosphorylation and cleavage of tau protein [15].

Positive labelling to $\tau$ was also observed in the cytoplasm of neurons of deep cortical areas of

5 frontal, parietal and temporal lobe of one bottlenose dolphin (Tursiops truncatus) with no clear NFT [16].

6 On the other side, well-defined NFT were recently observed in the frontal and parietal cortex, thalamus,

7 and cerebellum, of one bottlenose dolphin and three striped dolphins (Stenella coeruleoalba) [14].

Early-onset Alzheimer disease (EOAD), which presents in patients younger than 65 years, has

9 frequently been described as having the same neuropathological hallmarks than late-onset Alzheimer disease (LOAD). However, higher burdens of neuritic plaques and NFT in frontal and parietal lobes have

11 been found in EOAD than in LOAD patients [17]. On the other side, LOAD is more prevalent and generally has a more slowly progressing course as compared to EOAD [18]. While LOAD is consistently associated with aging [19], the plot thickens. In fact, vascular contributions to cognitive impairment and dementia (VCID; so called 'vascular dementia', 'vascular cognitive impairment' or 'vascular contributions to dementia') have been linked to AD [20]. Even though, the mechanisms by which hypoperfusion influences AD neuropathology remain unknown; decreased blood flow to the CNS in humans is classically associated with AD-related pathology. Some studies suggested that alterations in the CNS vasculature impair clearance of $\mathrm{A} \beta$, and thereby accelerate the progression of $\mathrm{AD}[21]$. histopathological hallmarks: A $\beta$ deposition and NFT formation. However, there are no natural animal models with comparable neurodegenerative findings. Moreover, most research into AD has been performed using transgenic rodents [6]. (toothed whales). Cetacea along with manatees (Sirenia) are the only mammals that are fully adapted to

26 life in water [22]. Toothed whales are hunters while baleen whales have plates along their upper jaws 27 used to filter food from the water column. One of the most fascinating characteristics of the toothed 28 whales is the exceptionally large size of the brain, both in absolute and in relative terms, and the extremely dense folding of the neocortex [23]. Cetaceans are homeotherms and long-lived top predators, which are at high risk of bioaccumulation and biomagnification of a variety of chemical pollutants [24]. 

and it has been suggested that dolphins might be one of the very few potential natural models of AD [14$16,25-29]$.

Among toothed whales, the beaked whales (BW; family Ziphiidae) are particularly cryptic and comprise more than 22 different species [30]. BW routinely dive deeper than 1,000 $\mathrm{m}$ for about one hour in order to hunt deep-water squid and fish [30]. They surface with a substantial oxygen debt that is paid off in a prolonged surface time that includes a series of shallow non-foraging dives [30, 31].

In the last years, BW received public attention after a series of mass-strandings caused by midfrequency naval sonars [32-34]. Decompression-like sickness (DCS) in the stranded animals was linked to naval mid-frequency sonar use.

A Cuvier's beaked whale (Ziphius cavirostris) broke the diving record at 3,000 m-depth lasted for two hours [30]. This is by far the deepest dive recorded for any air-breathing endotherm animal. Diving mammals are regularly exposed to hypoxic conditions during breath-hold diving and a large body of literature has addressed how they maintain their body functions [22, 35-37]. Diving mammals rely on a large blood volume rich in hemoglobin and in skeletal muscles with high concentrations of myoglobin, resulting in an enhanced capacity for tissue oxygen storage [37]. Furthermore, molecular adaptations have also been demonstrated in the diving brain. Williams et al. (2008) described that neural globin proteins, neuroglobin and cytoglobin, facilitate the movement of oxygen from blood to neural tissues [38]. The concentration of these neural globins is inversely related to maximum dive duration in marine mammals: deep divers preferentially rely on circulating globins in the brain while faster swimming coastal species use enhanced neural globin proteins stores [38]. Neuroglobin is involved in conferring hypoxia tolerance in the diving brain [39], scavenging reactive oxygen and nitrogen groups and so defending against cellular damage [40]. Cetaceans evolved a strategy by maintaining remarkably high levels of neuroglobin mRNA in their brains [39]. Induction of resident neural globins, particularly neuroglobin, has been associated with neuronal survival following cerebrovascular accidents such as stroke [41]. Hence, during evolution, cetaceans had then increased their tolerance to hypoxia and decreased metabolism during dives. 
1 to the brain during aging or hypoxic conditions has been demonstrated as a contributing factor to

2 hypometabolism [19]. In AD patients, the brain regions with hypometabolism can trigger overexpression

3 of APP and decrease the clearance of A $\beta$. A $\beta$ and hypoxia can evoke inflammation, oxidative stress and

4 eventual neuronal cell death [19].

5 On the other side, beneficial effects of the hyperbaric oxygen therapy (HBOT) have been

6 described, holding great potential for the treatment of $\mathrm{AD}$ [43]. HBOT comprises the medical

7 administration of $100 \%$ oxygen at conditions greater than 1 atmosphere absolute. The therapy seems to

8 reduce hypoxia, amyloid burden, and $\tau$ phosphorylation and seems to meliorate symptoms experienced by

9 patients with $\mathrm{AD}$ [43], but the results should be interpreted carefully due to its oxygen toxicity

10 (heightened oxidative stress) [44].

\section{RESULTS}

We detected positive immunolabeling of varying intensity and extent for A $\beta$, NFT or both in 6 out of $9(67 \%)$ animals (table 1). The immunohistochemical findings in these six animals are summarized 14 as follows.

Case 1 (Stenella frontalis, elderly, Fig. 1) presented A $\beta$ plaques in the frontopolar cortex. Also, there was strong and diffuse nuclear A $\beta$ labeling throughout the five neuronal layers of the frontopolar cortex involving the 3 types of neurons: pyramidal, granular, and Von Economo neurons, a type of large spindle-shaped neurons in layer V. Intranuclear staining was also detected in Purkinje neurons of the anterior and posterior cerebellum. The frontopolar cortex had scattered cortical neurons with diffuse cytoplasmic NFT labeling. of the frontal neocortex and in the cerebellar Purkinje neurons. A $\beta$ plaques were not observed.

24 labeling to NFT in Purkinje neurons. This animal also had cerebral nasitremiasis confined to the forebrain (unpublished data).

NFT in scattered Purkinje neurons. 
2 cytoplasmic labeling for NFT in Purkinje neurons.

\section{DISCUSSION}

$4 \quad$ Herein, we present immunohistochemical evidence of CNS positive labeling for A $\beta$ and NFT in $56 / 9(67 \%)$ animals, representing three odontocete species. A $\beta$ immunopositivity involved cerebral and 6 cerebellar neurons and A $\beta$ plaques, and NFT immunopositivity was confined to cerebellar Purkinje 7 neurons with granulovacuolar degeneration as well as in the cytoplasm of scattered frontopolar neurons as 8 diffuse staining. These findings were more extensive in deep and long-lasting diver species (one $Z$.

9 cavirostris and two M. densirostris); however, they were also found in one elderly and two adult, 10 shallow-diver species, namely S. frontalis. Two of three BW positive for A $\beta$ and NFT were subadults and 11 the other was adult. Based on these results, we present a novel hypothesis that considers hypoxia as one of the most important risk factors that could contribute to NDD in cetaceans, with special attention to BW

13 (Fig. 3), alongside to other proposed risk factors/causes proposed by other authors [14, 25, 27, 28, 33].

\section{Intranuclear neuronal A $\beta$-labeling: what does it mean?}

Intranuclear neuronal A $\beta$-labeling is barely described in the literature. The cell nucleus is a major target of amyloid-like protein fibrillation in a variety of disorders that are characterized by widespread aggregation of proteins with instable homopolymeric amino acid repeats, ubiquitin, and other proteinaceous components [4]. [45]. Intranuclear neuronal A $\beta$-labeling was observed in two cases in this study: an elderly $S$. frontalis and a subadult $Z$. cavirostris. The later was one of the $14 \mathrm{BW}$ stranded in close temporal and geographic association with an international naval exercise (Neo-Tapon 2002) held on September $24^{\text {th }}$, $2002[46,47]$. In this animal, we propose intranuclear neuronal $\mathrm{A} \beta$ expression having a neuroprotective role to hypoxia. In fact, previous studies have demonstrated that intracellular $A \beta 42$ accumulation is an early event in neuronal dysfunction. Furthermore, preventing intraneuronal A $\beta 42$ aggregation may be an important therapeutic direction for the treatment of $\mathrm{AD}$ [48]. Even though the mechanism is still unknown and there is no confirmation to date on $A \beta$ binding to DNA, the nuclear localization of $A \beta$ might play a role in bringing about changes in DNA topology, modulating both helicity and superhelicity in super coiled DNA [45]. In addition, AD-vulnerable brain regions specifically accumulate $\gamma$-cleaved A $\beta 42$, suggesting that intraneuronal A $\beta 42$ immunoreactivity appears to precede both NFT and A $\beta$ plaque deposition [48]. 
Although the role of nuclear amyloid is still unknown, the $A \beta$ intranuclear expression provides

2 new insights regarding cerebral safeguards for hypoxic-ischemic brain injury from accidents or disease.

3 While it was initially thought that nuclear amyloid is responsible for neural cell death, time-resolved experiments that correlate nuclear amyloid and neurodegeneration on the single cell level also suggest a cell protective role [4].

\section{Granulovacuolar degeneration for selectively vulnerable neurons}

Neuronal granulovacuolar degeneration (GVD) is one of the histopathological hallmarks of AD and is defined as electron-dense granules ( 0.5 to $1.5 \mathrm{~mm}$ in diameter) within double membrane-bound cytoplasmic vacuoles, mainly in the hippocampal pyramidal neurons [49]. The granules are composed of several components including neurofilament proteins, ubiquitin, phosphorylated $\tau$, and other microtubuleassociated proteins [50]. To the best of the authors' knowledge, GVD has not been observed in the very few studies performed in aged rats, wolverines, and dogs [51-53]. Even though, in the gray mouse lemur, $\tau$ proteins was observed as clumps of thick granules located close to the membrane of the neuronal perikarya and the dendrites [12].

GVD was observed in the Purkinje neurons of the anterior and posterior cerebellum of two BW and one Stenella frontalis. GVD is not pathognomonic of AD and can be observed in other NDD and in brains of non-demented aged people [54]. GVD inclusions and hyperphosphorylated forms of the microtubule-associated protein $\tau$ (which comprise the neurofibrillary changes) are present in the same neurons, and neurons with GVD frequently occur together with those containing NFT [54]. Several antibodies to $\tau$ inconsistently label GVD indicating that the pattern of GVD immunoreactivity shows a phosphorylation state (hyperphosphorylation) of the granules that is similar to that of NFT [54]. GVD inclusions are autophagic vacuoles that may sequester proteins. Their role is not yet resolved and may be interpreted as either a cellular defense mechanism or an indicator of impaired cellular functioning [54].

24 Regardless of whether GVD is a cellular defense mechanism or not, this finding has never been documented in any marine mammal species [55]. We did not evaluate the hippocampal formation in this preliminary study; future studies should address potential key roles of this neuroanatomical locale, so tiny in cetaceans, in NDD in marine mammals [56]. Certain structures of the hippocampus are vulnerable as are the Purkinje neurons of the cerebellum [57]. This would provide further support to "selectively vulnerable" regions of the brain under hypoxic conditions. Lastly, the cerebellum has to be firmly considered as a key protagonist in the pathophysiology and manifestations of AD and other NDD [58, 
1 59], including marine mammal species. Interestingly, Purkinje cell loss and cerebellar astrocytosis in

2 familial Alzheimer's disease (FAD) are greater than in $\mathrm{LOAD}$, indicating that the cerebellum is more

3 affected in FAD than in LOAD [60].

$4 \quad$ A $\beta$ and NFT: no cross-reactivity of shared epitopes

The specific patterns of intraneuronal A $\beta$ and granular (and in a few cases, diffuse) NFT labeling would exclude the possibility of cross-reactivity of shared epitopes. Additionally, the specificity of the A

$7 \quad \beta$ uptake was attested to by comparison with Congo red staining; there was complete correlation

8 between the Congo red staining visualized in the neuronal nuclei and the reference compound $\mathrm{A} \beta$.

9 Moreover, the Congo red staining validated the immunopositivity not only in the elderly plaques but also 10 in the nuclei of the neurons and confirmed the $\mathrm{A} \beta$ uptake.

\section{CONCLUSIONS}

13 NDD in humans, i.e., A $\beta$ and NFT labeling, in different CNS locales of odontocete cetaceans. These

14 findings could be linked to hypoxic phenomena, as they were more extensive in the brains of deep diver 15 cetacean species, specifically beaked whales, and not only in aged individuals. Therefore, a novel 16 hypothesis linking hypoxia and NDD microscopic hallmarks in cetaceans is proposed.

17 This study presents the first description of $\mathrm{A} \beta$ and NFT in the brain of BW, adding also to the 18 few descriptions of GVD in the brain of non-experimental animals, being specifically the first report of 19 GVD in the cerebellum. This research further confirms the rarely reported intranuclear expression of A $\beta$. 20 Despite their adaptations, diving mammals could be vulnerable to sustained and repetitive CNS hypoxia.

21 Future investigations should also address potential neuroprotective adaptations in these species. Drawing 22 a specific fingerprint-like pattern of the behavior of neuronal and non-neuronal components of the brain

23 [33] could help to better understand the pathogenesis of some NDD. Further research is needed in

24 cetaceans, with special attention to deep diver species and BW; comparative pathological and

25 neuroprotective investigations may prove of great value to AD and other NDD in humans.

26 In summary, these results found evidence of both amyloid deposits and tau pathology in stranded

27 toothed whales, making them one of very few naturally occurring models of AD as well as other NDD.

28 Finally, NDD should be reclassified according to the cell biology pathways affected rather than

29 only by the mere presence of plaques and tangles as in AD. Nowadays, there is evidence that some NDD 
1 have both clinical and genetic overlaps and that most of the patients with $\mathrm{AD}$, if they survive long

2 enough, develop a movement disorder of the Parkinson's type. Even if we detected A $\beta$ deposition and

3 NFT by immunohistochemistry as GVD, we do not state these animals have AD. We strive to provide

4 histopathological and immunohistochemical commonalities with human NDD, including AD and surmise

5 some factors, particularly hypoxia, may play a role in their neuropathogenesis.

\section{METHODS}

\section{Animals, brain processing methodology and histopathological analysis}

One of the main challenges of working with cetaceans' brains is to establish a valid methodology for an optimal manipulation and fixation of such specimens, for neuroanatomical and neuropathological studies. Such difficulties are related to (1) their brain size, (2) the logistic difficulties and laboratorial complexity to achieve a large sample size from certain elusive species, such as the BW - here the Cuvier's beaked whale (Ziphius cavirostris) and the Blainville's beaked whale (Mesoplodon densirostris), and (3) the difficulties to obtain 'extremely fresh' brain samples from stranded individuals. six different odontocete species that stranded and died along the coastline of the Canary Islands $\left(28^{\circ} 17^{\prime} 29^{\prime \prime} \mathrm{N}, 16^{\circ} 37^{\prime} 44^{\prime \prime} \mathrm{W}\right.$; Spain), were included in this study. On one side, five deep divers animals were included in the study: one Cuvier's beaked whale, two Blainville's beaked whales, one short-finned pilot whale (Globicephala macrorhynchus), one Risso's dolphin (Grampus griseus). Additionally, 4 shallow divers were also added: three Atlantic spotted dolphins (Stenella frontalis), and finally one captive neonatal bottlenose dolphin, which died of natural cause, was examined as control.

23 Neither experiments were performed on live animals, nor these animals were sacrificed for the purposes 24 of the study.

The animals were of different age categories: elderly $(\mathrm{n}=1)$, adult $(\mathrm{n}=5)$, subadult $(\mathrm{n}=2)$, newborn

$26(\mathrm{n}=1)$, based on total body length, gross and microscopic gonadal appearance [61], and systemic gross

27 and microscopic features, e.g., pronounced tooth wear, neuronal lipofuscinosis, greater amount of

28 neuromelanin in the locus coeruleus [26] or substantia nigra, intraneuronal polyglucosan bodies,

29 leptomeningeal fibrosis, and choroid plexus hyalinosis. 
2 in $4 \%$ formaldehyde solution in phosphate-buffered saline (PBS; $\mathrm{pH} 7.4$ ) and processed for

3 neuroanatomical and neuropathological analysis as described by Sacchini et al. [26]. After rinsing in PBS, samples were cryoprotected in $30 \%$ sucrose solution in PBS (pH 7.4) at $4^{\circ} \mathrm{C}$, to avoid freezing artifacts. The samples were immersed in a mixture of PBS-sucrose and Optimum Cutting Temperature formulation (OCT) (1:1) overnight. The day after, the samples were included in a mold using the same mixture, were rapidly frozen and 50-60 $\mu$ m-thick serial sections were obtained employing a cryostat (Leica CM1950, Nussloch, Germany). Sections were stored in PBS (pH 7.4) solution with sodium azide $(0.01 \%)$

Additionally, for microscopic analysis, formalin-fixed, paraffin-embedded (FFPE) tissue sections were processed as routine, cut at $5 \mu \mathrm{m}$-thick and stained with hematoxylin and eosin.

\section{Immunoperoxidase staining}

The immunoperoxidase staining procedure was carried out on free-floating sections as described in Sacchini et al. [26]. Commercially available, human-oriented primary antibodies (pAbs) used were a monoclonal anti-A $\beta$ (1:100, clone H31L21, Invitrogen, Carlsbad, CA), and a polyclonal anti-NFT (1:100, Invitrogen) incubated 48 hours at $4^{\circ} \mathrm{C}$. To block non-specific binding, sections were incubated in a solution containing normal goat serum (S-1000, Vector Laboratories, Burlingame, CA), and 0.5\% Triton X-100 (Merck, Darmstadt, Germany). The sections were then incubated for 45 minutes with a biotinylated goat anti-rabbit antibody (BA-1000, Vector Laboratories) diluted 1:200 in a solution containing 1\% normal goat serum in PBS. No block for endogenous biotin was used. The immunoreactions were visualized either by 3,3'-diaminobenzidine (DAB) peroxidase kit (SK-4100, Vector Laboratories, city, country) followed by counterstaining with thionine, or by 3-amino-9ethylcarbazole (AEC) peroxidase kit (Vector Laboratories, SK-4200) without counterstaining.

\section{Bennhold's Congo Red stain}

Congo red is the most popular dye used as a probe for diagnosing amyloidosis also in AD brains. The Bennhold's Congo red stain is commonly used for the detection of amyloid on FFPE and frozen tissue sections [62]. The amyloid deposits are stained red and the nuclei are stained blue. FFPE samples were deparaffinized with xylene and rehydrated in graded ethanol. Sections were stained with Congo red solution for 1 hour, rinsed in distilled water, differentiated quickly in alkaline alcohol solution, and 
1 counterstained with Mayer's hematoxylin. The positive control was a kidney from a dog with severe renal

2 amyloidosis.

\section{Abbreviations}

5 AD Alzheimer's disease; AEC 3-amino-9-ethylcarbazole; APP amyloid precursor protein; A $\beta \beta$-amyloid;

6 BW beaked whales; CNS central nervous system; DAB 3,3'-diaminobenzidine; DCS Decompression-like

7 sickness; EOAD Early-onset Alzheimer disease; FAD familial Alzheimer's disease; FFPE formalin-fixed

8 paraffin-embedded; GVD granulovacuolar degeneration; HBOT hyperbaric oxygen therapy; LOAD late-

9 onset Alzheimer disease; NDD neurodegenerative diseases; NFT neurofibrillary tangle; OCT Optimum

10 Cutting Temperature; pAbs human-oriented primary antibodies; PBS phosphate-buffered saline; $\tau$ tau

\section{Ethics approval and consent to participate}

13 The required permission for the management of stranded cetaceans anywhere within the Canarian

14 archipelago was issued by the environmental department of the Canary Islands' Government. No

15 experiments were performed on live animals because our work is based on dead stranded cetaceans.

\section{Consent for publication}

17 Not applicable.

\section{Availability of data and materials:}

19 All data for this study are included in the manuscript and the supplementary files. The datasets used 20 and/or analyzed during the current study are available from the corresponding author on reasonable 21 request.

\section{Competing interests}

23 The authors declare that they have no competing interests.

\section{$24 \quad$ Funding}

25 This work was supported by the National Projects CGL2015-71498-P and the Canary Islands

26 Government, which has funded and provided support to the stranding network.

\section{Author Contributions:}

28 SS and AF contributed conception and design of the study. SS, JD, AE, YP, YB, ES, MA, PH, and AF

29 contributed to organization of the databases and/or collected samples for histopathological and

30 immunohistochemical analysis. SS, YP, and ES contributed to laboratorial resources. SS wrote the first 
version.

\section{Acknowledgements}

The authors would like to thank Prof. Dr. Hannsjörg Schröder, Dr. Stefan Huggenberger, and Dr.

Christoph Köhler by extensive discussion of the findings herein presented and constructive comments.

\section{Authors Informations}

$7 \quad{ }^{1}$ Division of Histology and Animal Pathology, Institute for Animal Health and Food Security (IUSA),

8 Veterinary School, Universidad de Las Palmas de Gran Canaria, 35416 Arucas, Gran Canaria, Canary

9 Islands, Spain. ${ }^{2}$ Laboratory of Wildlife Comparative Pathology, School of Veterinary Medicine and

10 Animal Science, University of São Paulo, São Paulo, SP, Brazil. ${ }^{3}$ Texas A\&M Veterinary Medical

\section{REFERENCES}

1. Prince M, Wimo A, Guerchet M, Ali M, Wu Y, Prina M: World Alzheimer Report 2015: The global impact of dementia an analysis of prevalence, incidence, cost and trends. https://wwwalzcouk/research/WorldAlzheimerReport2015pdf Accessed September 1, 20192015.

2. Iqbal K, Grundke-Iqbal I: Alzheimer's disease, a multifactorial disorder seeking multitherapies. Alzheimer's \& Dementia: The Journal of the Alzheimer's Association 2010, 6(5):420-424.

3. Sun X, Chen WD, Wang YD: beta-Amyloid: the key peptide in the pathogenesis of Alzheimer's disease. Frontiers in pharmacology 2015, 6:221.

4. von Mikecz A: Pathology and function of nuclear amyloid. Nucleus 2014, 5(4):311-317.

5. Forny-Germano L, Lyra e Silva NM, Batista AF, Brito-Moreira J, Gralle M, Boehnke SE, Coe BC, Lablans A, Marques SA, Martinez AM et al: Alzheimer's disease-like pathology induced by amyloid-beta oligomers in nonhuman primates. The Journal of neuroscience : the official journal of the Society for Neuroscience 2014, 34(41):13629-13643.

6. Youssef SA, Capucchio MT, Rofina JE, Chambers JK, Uchida K, Nakayama H, Head E: Pathology of the Aging Brain in Domestic and Laboratory Animals, and Animal Models of Human Neurodegenerative Diseases. Vet Pathol 2016, 53(2):327-348.

7. Lemere CA, Oh J, Stanish HA, Peng Y, Pepivani I, Fagan AM, Yamaguchi H, Westmoreland SV, Mansfield KG: Cerebral amyloid-beta protein accumulation with aging in cotton-top tamarins: a model of early Alzheimer's disease? Rejuvenation research 2008, 11(2):321-332.

8. Geula C, Nagykery N, Wu CK: Amyloid-beta deposits in the cerebral cortex of the aged common marmoset (Callithrix jacchus): incidence and chemical composition. Acta neuropathologica 2002, 103(1):48-58.

9. Kimura N, Nakamura S, Goto N, Narushima E, Hara I, Shichiri S, Saitou K, Nose M, Hayashi T, Kawamura $\mathrm{S}$ et al: Senile plaques in an aged western lowland gorilla. Experimental animals 2001, 50(1):77-81.

10. Perez SE, Raghanti MA, Hof PR, Kramer L, Ikonomovic MD, Lacor PN, Erwin JM, Sherwood $\mathrm{CC}$, Mufson EJ: Alzheimer's disease pathology in the neocortex and hippocampus of the western lowland gorilla (Gorilla gorilla gorilla). The Journal of comparative neurology 2013, 521(18):4318-4338.

11. Rosen RF, Farberg AS, Gearing M, Dooyema J, Long PM, Anderson DC, Davis-Turak J, Coppola G, Geschwind DH, Pare JF et al: Tauopathy with paired helical filaments in an aged chimpanzee. The Journal of comparative neurology 2008, 509(3):259-270. 
12. Bons N, Rieger F, Prudhomme D, Fisher A, Krause KH: Microcebus murinus: a useful primate model for human cerebral aging and Alzheimer's disease? Genes, brain, and behavior 2006, 5(2):120-130.

13. Foster EA, Franks DW, Mazzi S, Darden SK, Balcomb KC, Ford JK, Croft DP: Adaptive prolonged postreproductive life span in killer whales. Science 2012, 337(6100):1313.

14. Gunn-Moore D, Kaidanovich-Beilin O, Gallego Iradi MC, Gunn-Moore F, Lovestone S: Alzheimer's disease in humans and other animals: A consequence of postreproductive life span and longevity rather than aging. Alzheimer's \& dementia : the journal of the Alzheimer's Association 2017.

15. Sarasa M, Pesini P: Natural non-trasgenic animal models for research in Alzheimer's disease. Current Alzheimer research 2009, 6(2):171-178.

16. Stylianaki I, Komnenou AT, Posantzis D, Nikolaou K, Papaioannou N: Alzheimer's diseaselike pathological lesions in an aged bottlenose dolphin (Tursiops truncatus). Veterinary Record Case Reports U6 2019, 7(1).

17. Palasi A, Gutierrez-Iglesias B, Alegret M, Pujadas F, Olabarrieta M, Liebana D, Quintana M, Alvarez-Sabin J, Boada M: Differentiated clinical presentation of early and late-onset Alzheimer's disease: is $\mathbf{6 5}$ years of age providing a reliable threshold? JOURNAL OF NEUROLOGY 2015, 262(5):1238-1246.

18. Panegyres PK, Chen HY: Differences between early and late onset Alzheimer's disease. American journal of neurodegenerative disease 2013, 2(4):300-306.

19. Ashok BS, Ajith TA, Sivanesan S: Hypoxia-inducible factors as neuroprotective agent in Alzheimer's disease. Clinical and experimental pharmacology \& physiology 2017, 44(3):327334.

20. Snyder HM, Corriveau RA, Craft S, Faber JE, Greenberg SM, Knopman D, Lamb BT, Montine TJ, Nedergaard M, Schaffer CB et al: Vascular contributions to cognitive impairment and dementia including Alzheimer's disease. Alzheimer's \& dementia : the journal of the Alzheimer's Association 2015, 11(6):710-717.

21. Koike MA, Green KN, Blurton-Jones M, Laferla FM: Oligemic hypoperfusion differentially affects tau and amyloid-\{beta\}. Am J Pathol 2010, 177(1):300-310.

22. Cozzi B, Huggenberger S, Oelschläger HA, Demma M, Gorter U, Oelschläger J: Anatomy of dolphins : insights into body structure and function. 2017.

23. Oelschläger HHA, Oelschläger JS: Brain, in: Perrin, W.F. et al. (2002). Encyclopedia of marine mammals. 2002:133-158.

24. Stavros H-CW, Bossart GD, Hulsey TC, Fair PA: Trace element concentrations in skin of free-ranging bottlenose dolphins (Tursiops truncatus) from the southeast Atlantic coast. Science of The Total Environment 2007, 388(1):300-315.

25. Di Guardo G: Alzheimer's disease, cellular prion protein, and dolphins. Alzheimer's \& dementia : the journal of the Alzheimer's Association 2018, 14(2):259-260.

26. Sacchini S, Arbelo M, Bombardi C, Fernández A, Cozzi B, Bernaldo de Quirós Y, Herráez P: Locus coeruleus complex of the family Delphinidae. Scientific reports 2018, 8(1):5486.

27. Davis DA, Mondo K, Stern E, Annor AK, Murch SJ, Coyne TM, Brand LE, Niemeyer ME, Sharp S, Bradley WG et al: Cyanobacterial neurotoxin BMAA and brain pathology in stranded dolphins. PLOS ONE 2019, 14(3):e0213346.

28. Di Guardo G: Do dolphins get Alzheimer's disease? The Veterinary record 2019, 185(24):762.

29. Di Guardo G: Cetaceans, models for human disease? Research in Veterinary Science 2018, 119:43-44.

30. Madsen PT, Aguilar de Soto N, Tyack PL, Johnson M: Beaked whales. Curr Biol 2014, 24(16):R728-730.

31. Tyack PL, Johnson M, Soto NA, Sturlese A, Madsen PT: Extreme diving of beaked whales. Journal of Experimental Biology 2006, 209(21):4238-4253.

32. Fernández A, Sierra E, Martín V, Méndez M, Sacchini S, Bernaldo de Quirós Y, Andrada M, Rivero M, Quesada O, Tejedor M et al: Last “Atypical” Beaked Whales Mass Stranding in the Canary Islands (July, 2004). J Marine Sci Res Dev 2012, 2(2).

33. Fernández A, de Quirós YB, Sacchini S, Sierra E: Pathology of Marine Mammals: What It Can Tell Us About Environment and Welfare. In: Marine Mammal Welfare: Human Induced Change in the Marine Environment and its Impacts on Marine Mammal Welfare. edn. Edited by Butterworth A. Cham: Springer International Publishing; 2017: 585-608.

34. Fernandez A, Arbelo M, Martin V: Whales: no mass strandings since sonar ban. Nature 2013, 497(7449):317. 
Fahlman A, Olszowka A, Bostrom B, Jones DR: Deep diving mammals: Dive behavior and circulatory adjustments contribute to bends avoidance. Respiratory Physiology \& Neurobiology 2006, 153(1):66-77.

36. Tian R, Wang Z, Niu X, Zhou K, Xu S, Yang G: Evolutionary Genetics of Hypoxia Tolerance in Cetaceans during Diving. Genome biology and evolution 2016, 8(3):827-839.

37. Ponganis PJ: Diving Physiology of Marine Mammals and Seabirds. Cambridge: Cambridge University Press; 2015.

38. Williams TM, Zavanelli M, Miller MA, Goldbeck RA, Morledge M, Casper D, Pabst DA, McLellan W, Cantin LP, Kliger DS: Running, swimming and diving modifies neuroprotecting globins in the mammalian brain. Proc Biol Sci 2008, 275(1636):751-758.

39. Schneuer M, Flachsbarth S, Czech-Damal NU, Folkow LP, Siebert U, Burmester T: Neuroglobin of seals and whales: Evidence for a divergent role in the diving brain. Neuroscience 2012, 223:35-44.

40. Fago A, Hundahl C, Malte H, Weber R: Functional Properties of Neuroglobin and Cytoglobin. Insights into the Ancestral Physiological Roles of Globins. IUBMB Life 2004, 56(11):689-696.

41. Sun Y, Jin K, Peel A, Mao XO, Xie L, Greenberg DA: Neuroglobin Protects the Brain from Experimental Stroke in vivo. Proceedings of the National Academy of Sciences of the United States of America 2003, 100(6):3497-3500.

42. Li L, Zhang X, Yang D, Luo G, Chen S, Le W: Hypoxia increases Abeta generation by altering beta- and gamma-cleavage of APP. Neurobiology of aging 2009, 30(7):1091-1098.

43. Shapira R, Solomon B, Efrati S, Frenkel D, Ashery U: Hyperbaric oxygen therapy ameliorates pathophysiology of 3xTg-AD mouse model by attenuating neuroinflammation. Neurobiology of aging 2018, 62:105-119.

44. Huang X: Hyperbaric Oxygen Therapy for Alzheimer's Disease. EC pharmacology and toxicology 2018, 6(3):74-75.

45. Hegde ML, Anitha S, Latha KS, Mustak MS, Stein R, Ravid R, Jagannatha Rao KS: First evidence for helical transitions in supercoiled DNA by amyloid $\beta$ peptide (1-42) and aluminum. Journal of Molecular Neuroscience 2004, 22(1):19-31.

46. Arbelo M, Los Monteros AE, Herraez P, Andrada M, Sierra E, Rodriguez F, Jepson PD, Fernandez A: Pathology and causes of death of stranded cetaceans in the Canary Islands (1999-2005). Diseases of aquatic organisms 2013, 103(2):87-99.

47. Fernandez A, Edwards JF, Rodriguez F, Espinosa de los Monteros A, Herraez P, Castro P, Jaber JR, Martin V, Arbelo M: "Gas and fat embolic syndrome" involving a mass stranding of beaked whales (family Ziphiidae) exposed to anthropogenic sonar signals. Vet Pathol 2005, 42(4):446-457.

48. Gouras GK, Tsai J, Naslund J, Vincent B, Edgar M, Checler F, Greenfield JP, Haroutunian V, Buxbaum JD, $\mathrm{Xu} \mathrm{H}$ et al: Intraneuronal Abeta42 accumulation in human brain. Am J Pathol 2000, 156(1):15-20.

49. Braak H, Braak E: Neuropathological stageing of Alzheimer-related changes. Acta neuropathologica 1991, 82(4):239.

50. Yamazaki Y, Matsubara T, Takahashi T, Kurashige T, Dohi E, Hiji M, Nagano Y, Yamawaki T, Matsumoto M: Granulovacuolar degenerations appear in relation to hippocampal phosphorylated tau accumulation in various neurodegenerative disorders. PloS one 2011, 6(11):1-10.

51. Yu CH, Song GS, Yhee JY, Kim JH, Im KS, Nho WG, Lee JH, Sur JH: Histopathological and immunohistochemical comparison of the brain of human patients with Alzheimer's disease and the brain of aged dogs with cognitive dysfunction. Journal of comparative pathology 2011, 145(1):45.

52. Roertgen KE, Parisi JE, Clark HB, Barnes DL, O'Brien TD, Johnson KH: A beta-associated cerebral angiopathy and senile plaques with neurofibrillary tangles and cerebral hemorrhage in an aged wolverine (Gulo gulo). Neurobiology of aging 1996, 17(2):243-247.

53. Is M, Comunoglu NU, Comunoglu C, Eren B, Ekici ID, Ozkan F: Age-related changes in the rat hippocampus. Journal of Clinical Neuroscience 2007, 15(5):568-574.

54. Köhler C: Granulovacuolar degeneration: a neurodegenerative change that accompanies tau pathology. Acta neuropathologica 2016, 132(3):339-359.

55. Thal DR, Del Tredici K, Ludolph AC, Hoozemans JJM, Rozemuller JM, Braak H, Knippschild U: Stages of granulovacuolar degeneration: their relation to Alzheimer's disease and chronic stress response. Acta neuropathologica 2011, 122(5):577. 


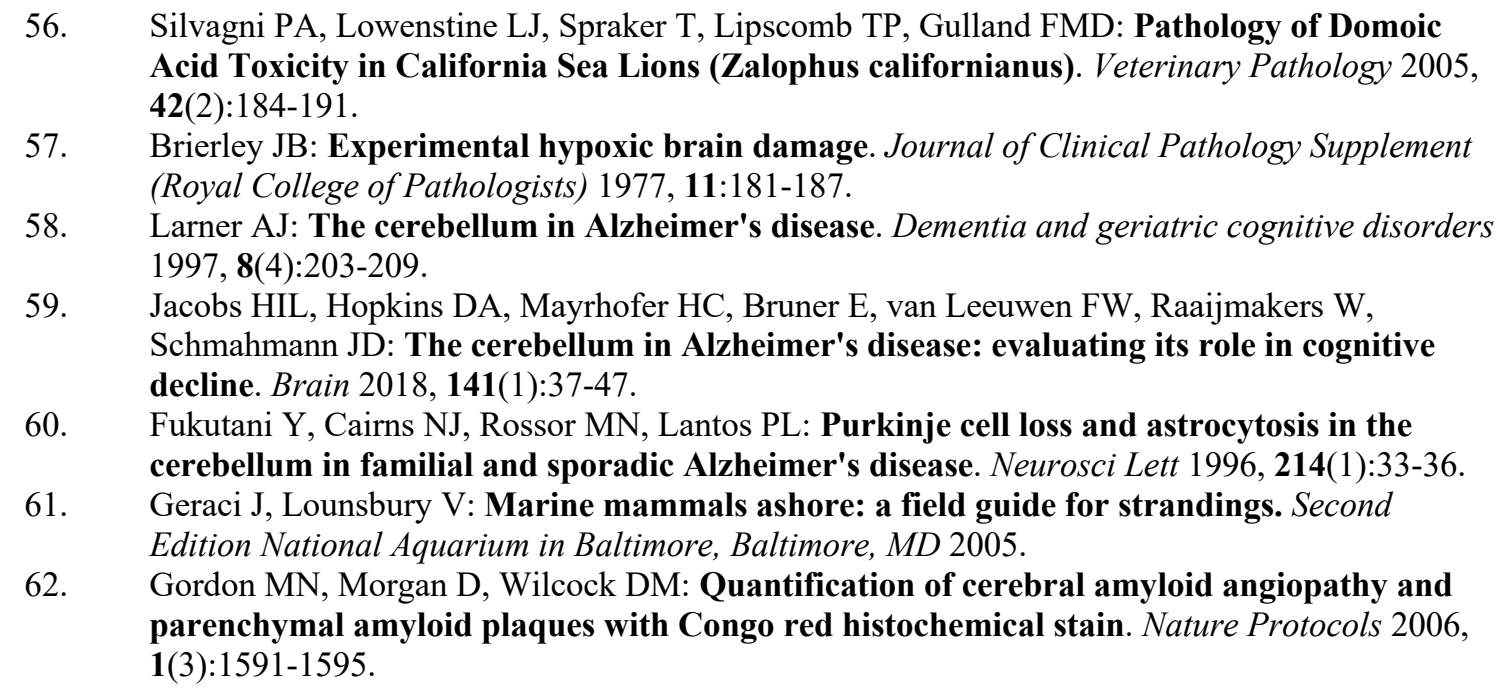

Figure 1: Case 1 (Stenella frontalis).

21 Strong and diffuse nuclear staining to $A \beta$ in the cortical neurons. $A \beta$ free-floating immunolabelling; DAB

22 not counterstained with thionine (A) Bennhold's Congo Red stain (B). Scale bar $=20 \mu \mathrm{m}$. A $\beta$-positive

23 aggregate in the frontopolar cortex (C). There are multiple irregular, slightly well-demarcated dense A $\beta$ -

24 positive extracellular/neuroparenchymal aggregates (D, asterisks) in the gray matter and subcortical white

25 matter. $A \beta$ free-floating immunolabelling; DAB counterstained with thionine.

26 Figure 2: Case 5 (Mesoplodon densirostris).

27 NFT-granulovacuolar labeling in Purkinje neurons (A-C). Purkinje cells have focal to diffuse granular

28 cytoplasmic NFT-positive labeling (A and C). Free-floating immunolabelling; DAB counterstained with

29 thionine (A and C). AEC not counterstained (B).

30 Figure 3: Neurodegenerative diseases in diving marine mammals (here represented a beaked whale) may

31 result from the interactive effects of multiple risk factors among which hypoxia could be one of the most

32 important.

\section{Supplementary material}

34 Table 1: Stranding and biologic data for nine odontocetes included in this study and

35 immunohistochemical results for $\beta$-amyloid and neurofibrillary tangle immunomarkers in cerebral cortex

36 and cerebellum. Semiquantitative analysis of intensity and extent:,- no;,+ mild; ++ , moderate; +++ , high.

$37 *$ neonatal dead animal used as control. NA, not applicable. 


\section{Figures}

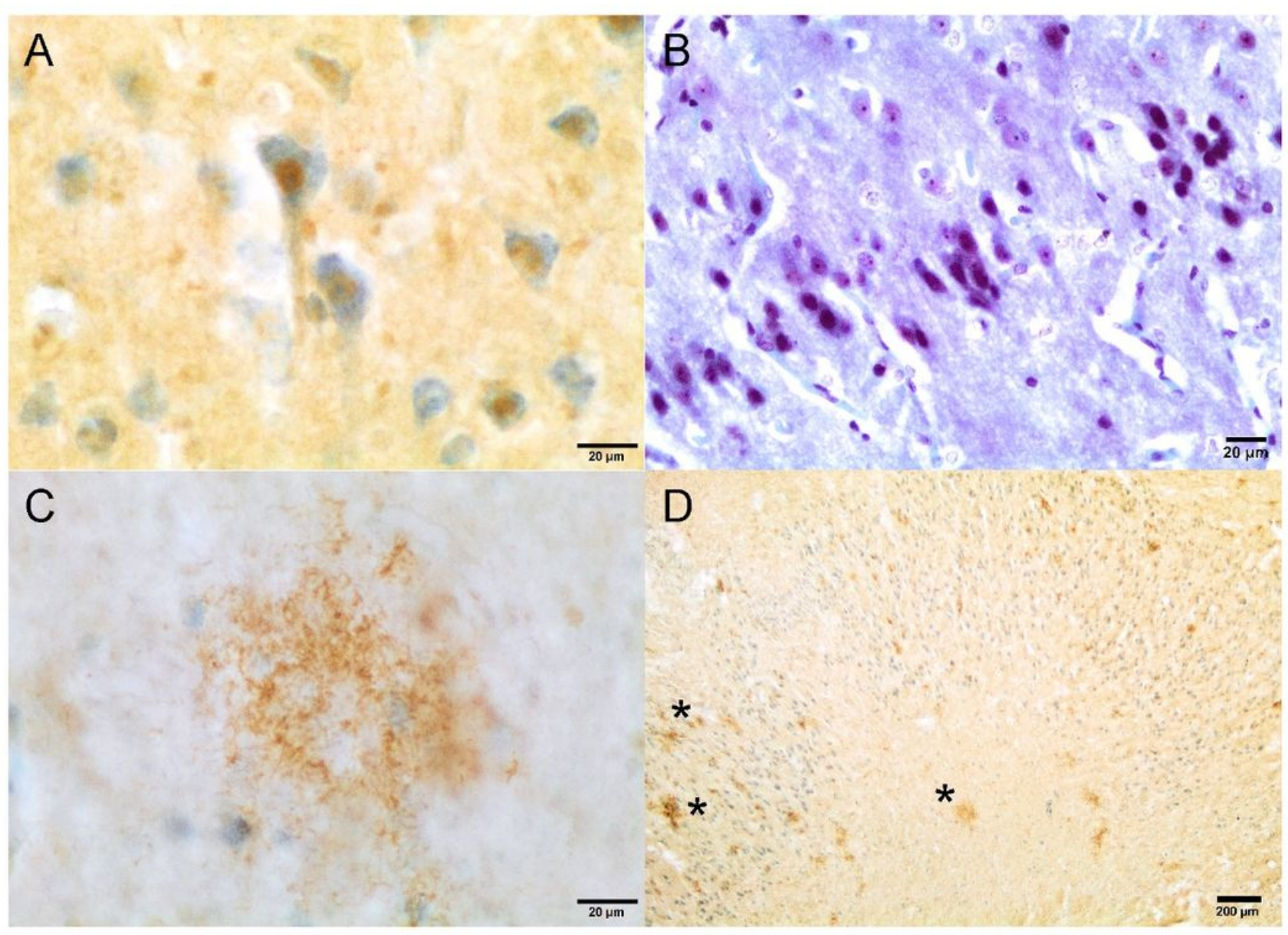

\section{Figure 1}

Case 1 (Stenella frontalis). Strong and diffuse nuclear staining to $A \beta$ in the cortical neurons. $A \beta$ freefloating immunolabelling; DAB 22 not counterstained with thionine (A) Bennhold's Congo Red stain (B). Scale bar $=20 \mu \mathrm{m}$. AB-positive aggregate in the frontopolar cortex (C). There are multiple irregular, slightly well-demarcated dense $A \beta$ - 24 positive extracellular/neuroparenchymal aggregates ( $D$, asterisks) in the gray matter and subcortical white matter. $A \beta$ free-floating immunolabelling; DAB counterstained with thionine. 


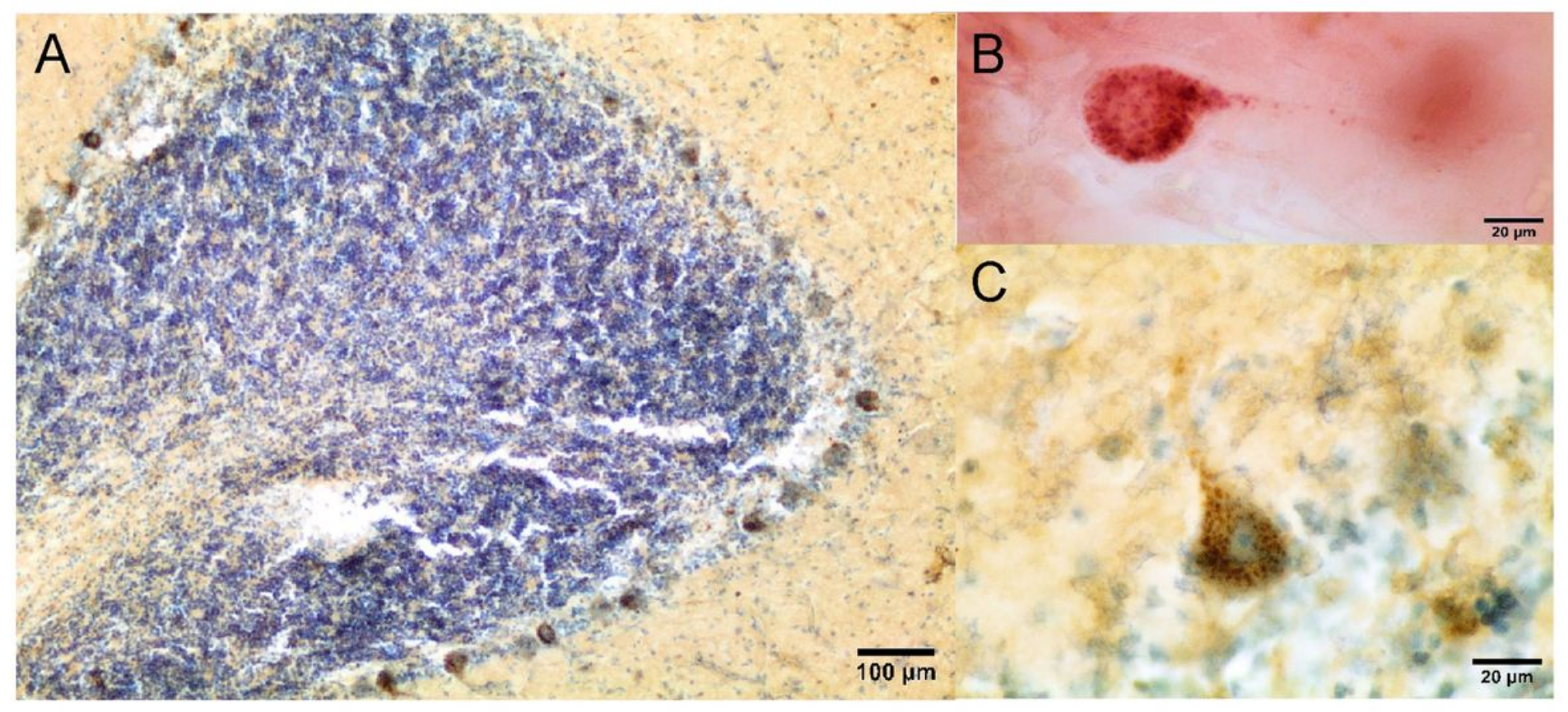

\section{Figure 2}

Case 5 (Mesoplodon densirostris). NFT-granulovacuolar labeling in Purkinje neurons (A-C). Purkinje cells have focal to diffuse granular cytoplasmic NFT-positive labeling ( $A$ and $C)$. Free-floating immunolabelling; DAB counterstained with thionine ( $A$ and $C)$. AEC not counterstained (B). 


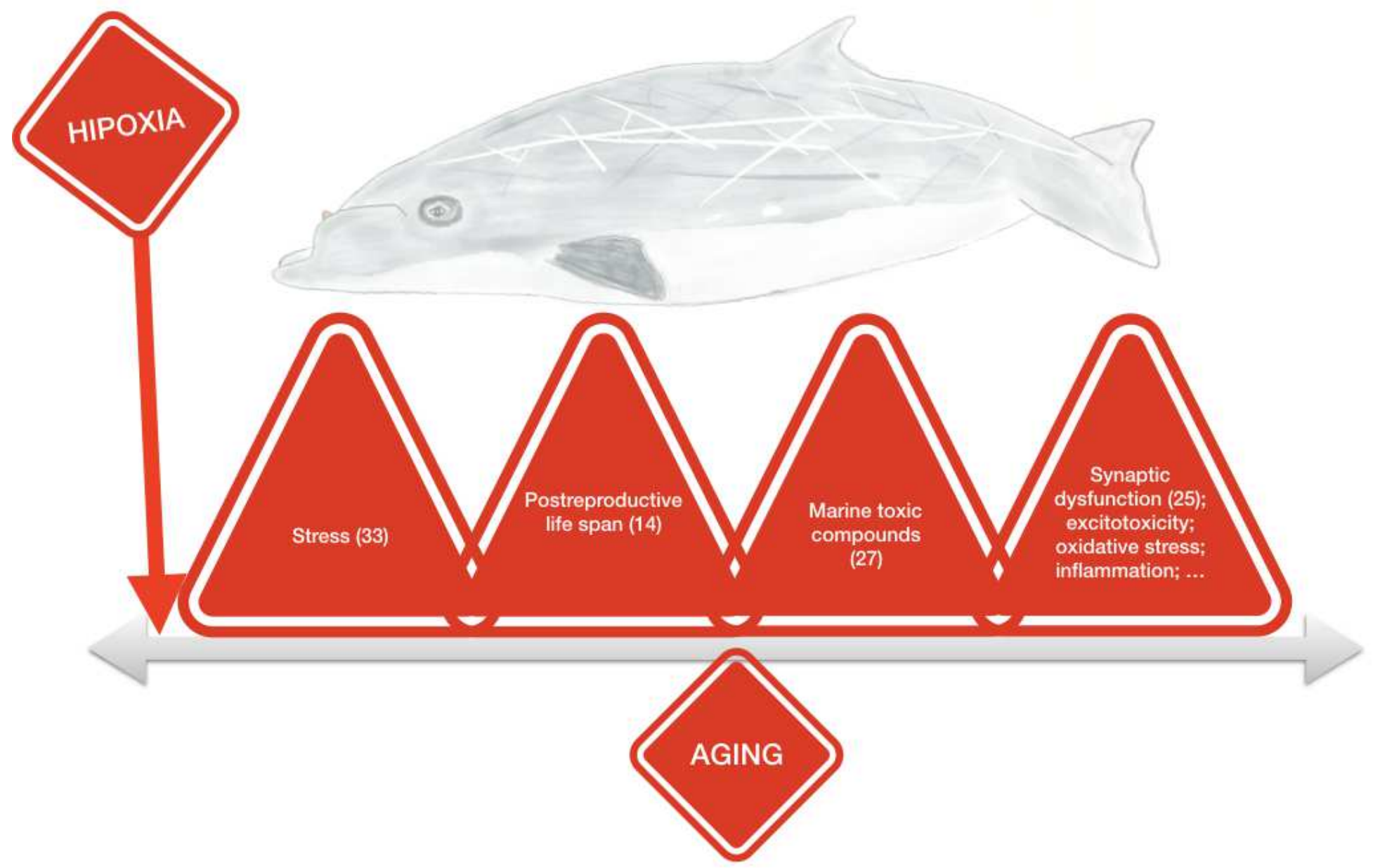

Figure 3

Neurodegenerative diseases in diving marine mammals (here represented a beaked whale) may result from the interactive effects of multiple risk factors among which hypoxia could be one of the most important.

\section{Supplementary Files}

This is a list of supplementary files associated with this preprint. Click to download.

- Table1Sacchinietal.2020.pdf 